entre

vinstia

Dol 10.5380/2238-0701.2015n10p261-277 


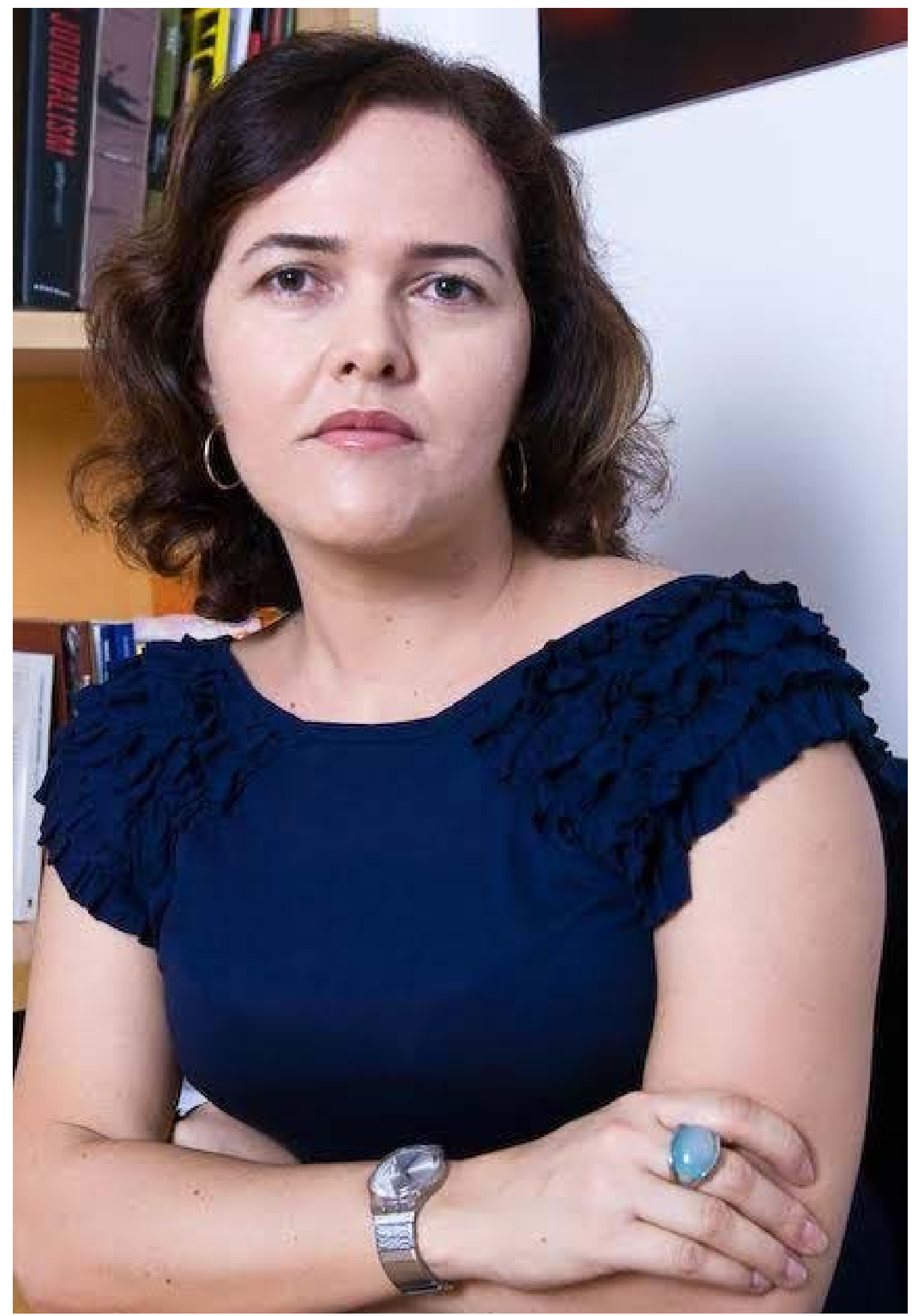




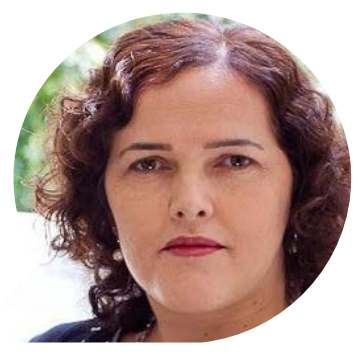

\title{
Os desafios do jornalismo e dos jornalistas no Século XXI: Entrevista com Suzana Barbosa'
}

\author{
The challenges of journalism and \\ journalists in the XXI century: \\ Interview with Suzana Barbosa
}

\author{
Los desafíos del periodismo $y$ \\ de los periodistas en el siglo XXI: \\ Entrevista con Suzana Barbosa
}

\begin{tabular}{c}
\hline KATI CAETANO $^{2}$ \\
\hline ZACLIS VEIGA $^{3}$ \\
\hline
\end{tabular}

1 Líder do Grupo de Pesquisa em Jornalismo On-line (Gjol). Coordenadora do Projeto Laboratório de Jornalismo Convergente (MCTI/CNPq/MEC/Capes 22/2014-2016; Fapesb, 2011-2014). É doutora (2007) em Comunicação e Cultura Contemporâneas pela UFBA, com pós-doutorado pela Universidade de Santiago de Compostela/Espanha (2008). Em 2005, realizou estágio doutoral no Laboratório de Comunicação e Conteúdos Online (LabCom), da Universidade da Beira Interior (Portugal). É diretora da Faculdade de Comunicação (Facom|UFBA, Set.2013 a Set.2017).

2 Doutora em Letras pela Universidade de São Paulo (FFLCH/USP); pós-doutora em Semiótica (CNRS/France) e em Ciências da Linguagem (Université de Paris 7). Professora titular e pesquisadora vinculada ao Programa de Pós-Graduação em Comunicação e Linguagens - PPGCom/UTP; líder do Grupo de Pesquisa "Interações Comunicacionais, Imagens e Culturas Digitais - Incom/ CNPq. Membro do Grupo de Pesquisa Comunicação e Cibercultura -Click/CNPq.

3 Doutora em Ciência da Informação pela Universidade Fernando Pessoa, Mestre em Multimeios pela Universidade de Campinas (Unicamp), Bacharel em Jornalismo pela Universidade Estadual de Ponta Grossa (UEPG). Professora Titular e coordenadora do curso de Jornalismo da Universidade Positivo. Membro do Grupo de Pesquisa Comunicação e Cibercultura - Click/CNPq. 
Resumo: A jornalista Suzana Barbosa é considerada uma das principais pesquisadoras brasileiras em jornalismo digital e temáticas afins, sendo uma das líderes do Grupo de Pesquisa em Jornalismo On-line (Gjol) do Programa de Pós-Graduação em Comunicação e Cultura Contemporâneas da Universidade Federal da Bahia (UFBA), pioneiro no Brasil sobre estudos na área. Nesta entrevista, com a autoridade de quem recebeu, em 2008, o Prêmio Adelmo Genro Filho da Associação Brasileira dos Pesquisadores em Jornalismo (SBPJor), de "Melhor Tese de Doutorado", trabalho que versou sobre jornalismo em base de dados, a pesquisadora assinala o marco histórico de vinte anos da vigência do jornalismo em redes digitais no país; aborda a recente crise que arrefeceu o lançamento de novos produtos jornalísticos autóctones no mercado digital; esclarece o uso de expressões como medialidade, transmidialidade e outras que marcam a comunicação na era da cibercultura; e defende a pesquisa como a forma mais segura de obter qualidade no ensino do jornalismo atual, marcado por permanências essenciais e por atualizações constantes em seu fazer e em suas formas de circulação e recirculação por inúmeras plataformas.

Palavras-chave: Jornalismo em redes digitais; Jornalismo em base de dados; Jornalismo móvel; Convergência jornalística; Ensino de jornalismo digital.

Abstract: The journalist Suzana Barbosa is considered one of the main Brazilian researchers in digital journalism and related themes, being one of the leaders of the Group of Research in Online Journalism (Gjol) of the graduate program in Communication and Contemporary Culture at the Federal University of Bahia (UFBA), pioneer in Brazil about studies in the area. In this interview, with the winner authority of the Adelmo Genro Filho Award of the Brazilian Association of Researchers in journalism, that she received in 2008, as "the best doctoral thesis in journalism", work about journalism in database, the researcher emphasizes the milestone of 20 years of journalism in digital networks in the country; discusses the recent crisis that cooled the launch of new products in the digital market journalistic; clarifies the use of typical expressions in the ciberculture times; and defends the research as the safest way to get quality in the journalism teaching. 
Keywords: Journalism on digital networks; Database journalism; Mobile journalism; Journalistic convergence; Digital journalism education.

Resumen: La periodista Suzana Barbosa es considerada una de las principales investigadoras brasileñas en periodismo digital y temas correlacionados, es una de los líderes del Grupo de Investigación en Periodismo online (Gjol) del Programa de Postgrado en Comunicación y Cultura Contemporánea de la Universidad Federal da Bahía (UFBA), pionero en Brasil en estudios realizados en el área. En esta entrevista, con la autoridad de quien recibió, en 2008, el Premio Adelmo Genro Filho de la Asociación Brasileña de Investigadores en Periodismo (SBPJor), de 'Mejor Tesis Doctoral en Periodismo ", obra que ha tratado del periodismo en la base de datos, la investigadora marca el hito de veinte años de vigencia del periodismo en redes digitales en el país; aborda la reciente crisis que ha enfriado el lanzamiento de nuevos productos periodísticos autóctonos en el mercado digital; aclara el uso de términos como medialidad, transmedialidad y otras que marcan la comunicación en la era de la cibercultura; $y$ aboga por la investigación como la forma más segura de obtener una educación de calidad en el periodismo actual, caracterizada por permanencias esenciales y actualizaciones constantes en su hacer y en sus formas de circulación y recirculación en numerosas plataformas.

Palabras clave: Periodismo en redes digitales; Periodismo en base de datos; Periodismo móvil; Convergencia periodística; Enseñanza de periodismo digital. 
O trabalho em editoria de tecnologia fez com que a jornalista Suzana Barbosa retornasse para a universidade: sua proposta de pesquisa de mestrado abordou o estudo das mudanças na produção jornalística a partir do surgimento e uso intensivo da Internet e da Web. A professora do Departamento de Comunicação e do Programa de Pós-Graduação em Comunicação e Cultura Contemporâneas da Faculdade de Comunicação da Universidade Federal da Bahia (Facom/ UFBA), que mantém uma produção científica volumosa, tem se dedicado intensamente à compreensão de um dos grandes fenômenos da cibercultura: as alterações no campo jornalístico em termos de produção de conteúdos, interatividade, redefinição da posição do receptor, mudanças radicais nas formas de distribuição da informação, bem como o papel do profissional jornalista no interior desta cultura digital. Nesta entrevista concedida às pesquisadoras paranaenses, Kati Caetano e Zaclis Veiga, a pedido da equipe editorial da revista Ação Midiática, Suzana Barbosa destaca, no final, a importância fundamental da pesquisa nas universidades para melhorar a qualidade da formação deste "novo jornalista".

\section{AÇÃO MIDIÁTICA: Como estudiosa das práticas jornalísticas, ex- plique que mudanças atuais devem ser ressaltadas nesse domínio.}

SUZANA BARBOSA: O jornalismo tem passado por muitas mudanças. Se formos recuar um pouco no tempo, desde o surgimento da chamada web comercial, em 1995 - que para o Brasil é uma data chave -, podemos dizer que estamos com 20 anos de vivência nesse novo padrão digital, que desde então tem afetado enormemente as práticas jornalísticas e o jornalismo de uma maneira mais ampla. Temos acompanhado e registrado mudanças consideráveis. Curiosamente, pude acompanhar essas mudanças antes como jornalista - atuando em redações de jornal e em sites jornalísticos - e foi o trabalho em editoria de tecnologia que me trouxe de volta para a universidade, com a intenção de propor projeto de pesquisa no mestrado para estudar essas mudanças a partir do surgimento da Internet e da Web e como elas interferiam na produção jornalística, afetando as práticas, os modelos de negócios, os formatos de produtos, os conteúdos, a linguagem e as narrativas. 
O marco de duas décadas de vigência do jornalismo em redes digitais no Brasil inicia-se com alguns experimentos, a exemplo do que realizou o Jornal do Commércio (Recife/PE), disponibilizando, em dezembro de 1994, um serviço próprio de envio de arquivos de texto via protocolo Gopher (sistema que permitia fazer ligações entre as páginas da World Wide Web, a WWW). Mas foi o Jornal do Brasil - JB (Rio de Janeiro, RJ) que lançou pioneiramente a edição completa de um jornal na web, em maio de 1995. Esse marco de duas décadas de jornalismo digital é, inclusive, o foco do livro-coletânea Ciberperiodismo en Iberoamérica (Fundación Telefónica/Ariel, 2015) para o qual produzi o capítulo sobre o Brasil. A publicação, coordenada pelo professor e pesquisador espanhol Ramon Salaverría (Universidad de Navarra), reúne artigos de 22 países da Iberoamérica.

Cito a publicação, pois creio que é uma importante referência na área, pela recuperação histórica sobre o desenvolvimento do jornalismo em redes digitais, nos permitindo verificar melhor as mudanças processadas desde o ponto de vista do negócio, do próprio jornalismo, do fazer jornalístico, da formação, da atuação dos profissionais, toda a reconfiguração e conformação de novos produtos e da própria circulação e recirculação desses produtos, da relação com o público/usuário - a maior interatividade e mudança no padrão de consumo que gerou uma audiência ativa/protagonista, ou a "cultura da participação", conforme Henry Jenkins cunhou em seu livro A Cultura da Convergência (2008). Nesse contexto, o uso das redes sociais para circulação e recirculação de conteúdos ainda gerou a "spreadable media" ou "media espalhável", de acordo com definição de Henry Jenkins, Sam Ford e Joshua Green, em Spreadable Media:Creating Value and Meaning in a Networked Culture (2013).

Vemos que, de 2005 para cá, essa proliferação de formatos em redes sociais tem trazido alterações no jornalismo no que diz respeito ao consumo e à circulação dos conteúdos e na própria relação entre a organização jornalística e a sua audiência, seu consumidor ou usuário. A própria atuação desse usuário a partir dos canais de interatividade conforma um contexto diferenciado. Podemos também fazer a leitura a partir da noção desse impacto que é obviamente tecnológico, mas não apenas, senão ficaríamos tão somente na questão de um determinismo tecnológico, e, na verdade, há que se considerar a questão social e cultural aí embutida que também propiciou alte- 
rações. A tecnologia é um fator importante? Sim, claro. E este é um tema de meu interesse desde o mestrado.

\section{AM E como evoluíram seus interesses de pesquisa nesta direção?}

SB No doutorado, o meu objeto de estudo foram as bases de dados no jornalismo digital, o que permitiu verificar a emergência do Paradigma Jornalismo Digital em Base de Dados, o qual tem auxiliado no melhor entendimento sobre o seu papel no jornalismo contemporâneo. Continuo pesquisando esta temática até mesmo por conta dos desenvolvimentos verificados. Por exemplo: o chamado Jornalismo Guiado por Dados (Data Journalism), o qual compreendo como uma das extensões para o Paradigma JDBD, uma vez que demarca a ampliação das possibilidades de emprego das bases de dados no processo de produção de conteúdos jornalísticos, no seu consumo, circulação e recirculação. Há que destacar, ainda, a inovação que as bases de dados proporcionam para os produtos jornalísticos, para os conteúdos e circulação desses produtos, para as mudanças nas relações entre os cibermeios e os usuários, para as transformações nas rotinas de trabalho dos jornalistas e demais profissionais que atuam em redações cada vez mais integradas e com o objetivo de criação para multiplataformas.

Atualmente, estou buscando perceber a inovação nos meios de maneira mais ampla e entendendo também, a partir dessa perspectiva (que é mais recente), a produção multiplataforma e de como as organizações de notícias têm trabalhado na reformulação das suas práticas, tanto do ponto de vista dos seus ciclos gerenciais, das suas rotinas produtivas, dos conteúdos, dos seus produtos em circulação e "recirculação" por distintas plataformas. Nesse sentido, o que temos como configuração de produtos mais recentes nesse panorama são aqueles produzidos para dispositivos móveis, tablets e smartphones.

\section{AM E o que não mudou nesse cenário?}

SB No caso do jornalismo é a sua essência que permanece, de como fazer bom jornalismo no sentido de que se deve perseguir a boa apuração e verificação, a qualidade da informação produzida e, principalmente, quanto ao aspecto da formação do profissional do jornalis- 
mo. O que faz a diferença sempre é essa distinção de cada profissional na sua formação, nessa atuação para a produção de conteúdos que de fato sejam relevantes.

É importante reforçar a função social do jornalismo, do papel do jornalista e da sua importância na sociedade atual. Quando vocês me perguntam: “O que não mudou?" e eu coloco questões relacionadas ao fazer profissional jornalístico e ao próprio profissional, é claro que temos aí embutidos aspectos que costumamos questionar e identificar como um bom e um mau jornalismo. Por exemplo, aquilo que se faz de modo preguiçoso é mau jornalismo, já aquilo que de fato é original, genuíno, dentro de uma produção jornalística séria, que busca recursos para melhor produzir seus conteúdos e melhor informar, é bom jornalismo. Então eu acho que essa função essencial se mantém para o jornalismo. Creio que isso não muda, mas temos novos métodos, recursos, mecanismos, meios, ferramentas para produzir e, mais do que isso, plataformas diversas por onde esses conteúdos jornalísticos hoje circulam, recirculam e são consumidos.

AM Diante da prática de análise de vários jornais online nesses vinte anos, você considera que os jornais, já nascidos ou que se transformaram em online, estão plenamente adaptados e exploram todas as possibilidades das novas tecnologias digitais ou percebe-se que ainda são poucos os recursos? Que recursos são mais constantes?

SB Em duas décadas de jornalismo em redes digitais passou-se por várias fases. A fase inicial era a da novidade, fortemente lançada, mas com uma base tecnológica que não permitia que se trabalhasse explorando as potencialidades e as funcionalidades do meio, porque não tínhamos banda larga, as conexões eram discadas e isso tudo tinha um impacto sobre aquilo que se produzia. Durante esses vinte anos, obviamente temos produtos que foram se atualizando e requalificando e outros que não se sustentaram tão bem, porque a produção jornalística demanda modelos de negócio e sustentação financeira.

Atualmente, temos um momento crítico de poucos investimentos nas organizações jornalísticas, ainda que tenhamos as marcas, que são aquelas do mainstream, que em geral mantém investimentos. Como referências, temos o The Guardian (Reino Unido), o New York Times (EUA), dentre outros cibermeios que já foram referências im- 
portantes, mas hoje sem tanto destaque, como o El País, na Espanha. No Brasil, temos casos igualmente importantes, mas é lamentável que hoje estejamos acompanhando uma redução dos quadros profissionais por conta de várias demissões. Podemos destacar os casos do $O$ Globo, da Folha de S. Paulo, da Gazeta do Povo, do Zero Hora e temos cases importantes que não estão no mainstream, como o próprio jornal Agência Pública que é referência no que diz respeito à produção jornalística independente, como meio independente. Estou falando de algumas marcas, que são aquelas associadas a organizações jornalísticas com forte atuação no impresso e que também vão se abrindo aos negócios digitais em outras plataformas.

Temos também aqueles meios originalmente criados e surgidos com a Web. Que fique claro que com esses meios originais (uma vez que eles já surgem com o foco em outra plataforma), as formas culturais e os parâmetros para produzir conteúdo já estão em outro patamar. Nesse caso, com melhor conhecimento de atuação. É óbvio que isso interfere naquilo que podemos identificar como casos ditos "ponteiros" ou mais inovadores.

Temos casos importantes de meios que nasceram digitais, como o The Huffington Post, que surgiu como um blog, foi crescendo como marca e hoje já está em outro patamar. Hoje também se fala de marcas que não são exclusivamente jornalísticas, mas que possuem grande potencial jornalístico, aliando o entretenimento, como é o caso do Buzzfeed. Então, temos um panorama internacional com casos interessantes. Em outubro de 2015, por exemplo, nasceu um novo cibermeio, o El Español, que é da Espanha, e que tem à frente Pedro J. Ramirez, que tornou-se referência como diretor do El Mundo.

\section{AM Tem-se a impressão de que nos primeiros 15 anos do que nós estamos chamando de era da Cibercultura, as coisas eram muito experimentais, muito na base de tentativa e erro, e parece que esse caminho vai se repetindo.}

SB Creio que quando se tem algo novo iniciando, como foi o caso da Web nos anos 1990, pouco se sabia como fazer. Engatinhava-se. Para usar a linguagem HTML (Linguagem de Marcação em Hipertexto), era preciso fazer tudo na mão, como, por exemplo, colocar um 
link, um hiperlink, elemento fundamental da linguagem hipertextual. O jornalista ia descobrindo e fazendo ao mesmo tempo. Pouco a pouco foi evoluindo até que se chegasse ao estágio de se ter sistemas de gerenciamento de conteúdo criados especificamente para uso no jornalismo. Mas demorou bastante, isso é lá no final da segunda metade dos anos noventa, início da década de 2000, principalmente aqui para nós, no Brasil.

Esta evolução gerou um impacto grande, porque com um sistema de gerenciamento de conteúdo apropriado é possível se fazer muito mais adequadamente e com a agilidade requerida. E é claro que também tivemos as evoluções no sistema das conexões com a banda larga e isso foi facilitando todo o processo. Hoje também temos acesso via wi-fi, de modo muito mais difundido. Ou seja, tivemos um crescimento muito importante e o Brasil, em relação ao contexto mundial, tem um espaço destacado. $\mathrm{O}$ próprio Instituto Reuters (The Reuters Institute for the Study of Journalism) tem feito pesquisas, considerando o mercado brasileiro e indicando tendências como, por exemplo, a de que o brasileiro quer pagar para consumir conteúdo jornalístico, uma outra questão que se discute bastante em relação ao modelo de negócios. A gratuidade é importante, mas não dá para ter todo o conteúdo gratuito, já que a produção jornalística demanda muito investimento. Uma produção jornalística qualificada é cara. A gente passou daquela fase de que tudo tem que ser gratuito. O El País viveu isso, o NYTimes também, daí veio uma fase de abrir tudo, depois, de novo, voltamos a ter uma parte aberta e outra paga, com modelos em que se pode ler dez textos livremente e depois é preciso pagar.

Enfim, temos aí uma diversidade de modelos em relação ao financiamento desses sites jornalísticos. Tanto no acesso web, quanto no acesso aos aplicativos jornalísticos em plataformas móveis, outro produto que entrou nessa galáxia que vai além do impresso, do que se produz para TV, para rádio, para web. Os aplicativos jornalísticos que se produzem para tablets e smartphones seriam os produtos mais recentes dessa galáxia informativa.

\section{AM É isso que você chama de jornalismo em contexto de mul- tiplataformas?}




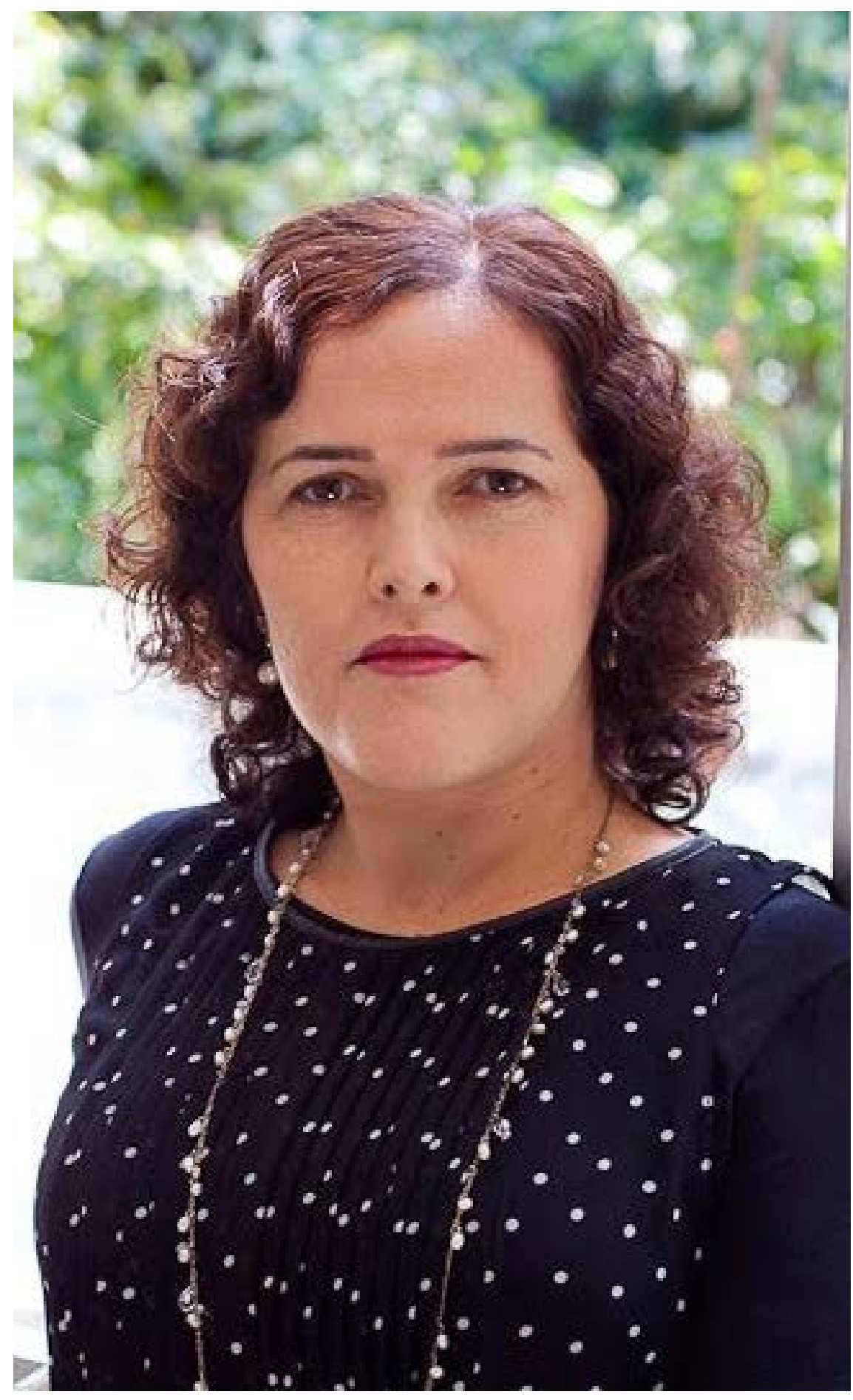


SB Sim. Nessa primeira década a questão da convergência também foi forte para as organizações jornalísticas, com reestruturação da sua cadeia produtiva, seu modelo de gerenciamento editorial e da forma de produzir. Tenho um artigo no qual denomino como "continuum multimídia” essa atuação das organizações jornalísticas convergentes. Precisa-se compreender que hoje não podemos mais dizer que a lógica, dentre os meios de uma mesma marca jornalística forte, é aquela de dizer que "meu jornal impresso compete com o meu site". $\mathrm{O}$ que se tem hoje é uma ação conjunta e integrada entre os meios, conformando processos e produtos, marcada pela horizontalidade dos fluxos de produção, edição e distribuição dos conteúdos. É isso que eu denomino de "continuum multimídia dinâmico". Para entender melhor, proponho essa denominação a partir da categoria da medialidade, colocada por Richard Grusin, em livro de 2010 (Premediation: Affect and Mediality After 9/11). Ele diz que: na contemporaneidade, a gente não pode mais falar nessa oposição entre os meios antigos tradicionais e os new media, porque a produção jornalística presente nos diversos formatos de conteúdo - sejam textos, fotos, áudios, vídeos, infográficos, newsgames, etc. - são todos criados, editados e distribuídos pelas organizações jornalísticas para as multiplataformas, e são totalmente realizados por profissionais empregando tecnologias digitais e em rede.

\section{AM Só para a gente esclarecer a questão do transmídia e do multi- mídia. Nós estamos em um momento transmídia ou multimídia?}

SB Transmídia é o termo que inclui também a noção da produção que considera as várias plataformas e as diversas mídias, sendo um termo com que alguns autores trabalham mais fortemente. Eu costumo trabalhar nas pesquisas e artigos mais com a noção da medialidade, da multimídia e da multiplataforma. Transmídia, no entendimento a partir do que Henry Jenkins trata no seu livro Cultura da Convergência (2008), está aplicado principalmente na área do entretenimento, para as indústrias criativas, considerando tanto os games quanto séries de TV e os produtos originados a partir deles. Quem trabalha mais com o audiovisual, por exemplo, costuma empregar muito o conceito de transmídia. 


\section{AM Você teria exemplo de alguma organização jornalística que investe, sistematicamente, em produtos autóctones para cada plataforma?}

SB Na pesquisa que iniciamos em 2011 no Projeto Laboratório de Jornalismo Convergente, financiado pela Fundação de Amparo à Pesquisa do Estado da Bahia (Fapesb), elegemos alguns casos de estudo, nacionais e internacionais, tendo o propósito de pesquisar e analisar os meios em multiplataformas. No decorrer do projeto e da pesquisa, em 2012, nos deparamos com produtos novos que foram surgindo e sendo lançados, fora do Brasil e depois aqui: produtos exclusivos para tablet. Daí que chegamos a essa denominação de aplicativos jornalísticos autóctones para tablets e smartphones. Se formos observar, 2012 é o ano em que houve um boom, um investimento muito maior de muitas organizações jornalísticas nesses produtos diferenciados para tablet, motivado pelo entendimento de que com o surgimento desse novo dispositivo - digo "novo" dentro da proposta que foi implementada pela Apple, em 2010, pois o tablet newspaper é um produto que foi pensado muito antes por Roger Fidler (autor do livro Mediamorphosis: Understanding New Media, de 1997) - se passaria a ter produtos jornalísticos, dentre outros, especificamente desenhados para ele.

Nós temos o caso do La Repubblica Sera, jornal digital italiano vespertino, ligado ao La Repubblica, porque verificou-se em pesquisas que o tablet é um produto cujo uso estava mais localizado no final da tarde, quando as pessoas já tinham saído do trabalho e estavam mais propensas a leituras longas, feitas com mais calma. Então, o La Repubblica Sera surgiu como produto que avaliamos como um autóctone para tablet. O Globo lançou O Globo a Mais que foi todo baseado no modelo do La Repubblica Sera e tivemos outros casos no Brasil, como o Estadão Noite, e o Folha 10 - que não era um vespertino, mas era outra conformação de produto para circular no tablet, que funcionava com a circulação apenas aos domingos.

Curiosamente, em 2015, tivemos as notícias do fechamento de alguns desses produtos, como o próprio O Globo a Mais e o Folha 10, ficando a promessa dessas organizações de que lançariam outros produtos para tablet. Isso é decorrência de um momento complexo do ponto de vista econômico e que também afeta as organizações jor- 
nalísticas. Então o boom que conseguimos perceber, em 2012, 2013 e 2014, agora em 2015 passa a ter um arrefecimento, mas possivelmente, mais à frente, outros produtos poderão aparecer voltados para o tablet ou, principalmente, para smartphones.

Existe um caso que é bem interessante que é o do canadense $\mathrm{La}$ Presse. Eles têm o La Presse + que é um produto para tablet, bastante diferenciado que se mantém, e foi criado depois desse hype que identificamos em 2012 e 2013. Ele está ativo e tem um modelo interessante, além de ser gratuito. A gente pode acessar no tablet e também via web. É um aplicativo referencial, nesse sentido. Temos casos de outros produtos/aplicativos para smartphone, como o Now do New York Times, um aplicativo bastante referenciado, e apenas disponível para smartphone nesse momento. Temos aí, mesmo diante da crise econômica, um novo cibermeio lançado (caso do El Español), que é interessante de se acompanhar. O The Guardian, curiosamente como meio, não é fechado, seus produtos são abertos na web e nas plataformas móveis. Hoje ele tem edições não só no Reino Unido, mas também na Austrália e nos Estados Unidos. Temos outras situações de meios. O próprio El País investiu numa versão brasileira, o El País Brasil, que se mantém. O NYTimes chegou a anunciar que investiria numa versão brasileira, mas até hoje não saiu..

AM Quais são as inflexões no ensino do jornalismo, quer dizer, o que as universidades precisam, podem, devem fazer, para formar esse sujeito que vai para o mercado, com as habilidades, que você afirmou que não mudam, mas também com essa habilidade de estar nessas novas plataformas em constante mutação?

SB A área em que nós estamos é um grande desafio. As mudanças são constantes, o que exige também atualização constante quanto aos métodos de ensino, em como ensinar a produzir novos produtos para as novas plataformas para que os alunos possam estar atualizados e bem preparados para a atuação profissional. Como costumamos dizer, temos parâmetros de como fazer um produto jornalístico com uma forma cultural consolidada, como se faz um telejornal numa emissora de TV aberta ou mesmo numa TV por assinatura, pois sabemos como é o padrão de um produto jornalístico tradicional. Há uma forma cultural estabelecida, lembrando Raymond Williams, 
quando fala da televisão como uma forma cultural no livro The television as technological form, (1974). Sabemos porque há um modelo estabilizado, de como ensinar a fazer jornalismo considerando os meios tradicionais.

Os desafios que temos hoje são realmente muito grandes, pois nos deparamos, às vezes, em situações onde os aspectos de estrutura em algumas faculdades não permitem completamente contemplar um ensino com essas práticas novas. Ainda estamos nos organizando. Em instituições de ensino particulares, às vezes, há mais estrutura. Mas como nem sempre há ênfase na investigação, na pesquisa, em alguns casos, não se tem tanto desenvolvimento. No caso específico do curso de Jornalismo, estamos passando também por adequação por conta das novas diretrizes, que devem estar implementadas já em 2016 como padrão da nova formação dos ingressantes. Então, com os eixos que estão colocados nas diretrizes, temos aquele essencial da fundamentação teórica nessa área, mas principalmente desafios em relação aos eixos relacionados às práticas.

Aqui na Faculdade de Comunicação da UFBA, desde 1999, realiza-se essa experimentação em relação ao ensino do jornalismo digital, por exemplo. Isso começou lá atrás, com disciplinas optativas, que uniam a ideia/noção da produção jornalística para a web e que depois foi estabilizado com disciplinas obrigatórias que foram entrando na grade curricular. $\mathrm{O}$ pioneirismo deveu-se, claro, às pesquisas desenvolvidas.

É um desafio constante buscar ensinar e fazer com que o aluno também aprenda o impacto disso não só a partir do surgimento dos dispositivos tecnológicos (computador, notebook, celular/smartphone, tablet, etc.), mas o que de fato significa para o jornalismo, para as práticas, para a atuação profissional, e para isso é imprescindível ter um curso com forte base de fundamentação teórico-conceitual, um corpo docente ativo na investigação. Para avançarmos precisamos de investimentos em pesquisa. É o que vai assegurar essa base no ensino do Jornalismo. Eu sou jornalista formada por essa instituição e acho que, obviamente, temos o dever agora, nessa nova posição como professora, de ensinar a fazer, da melhor maneira possível, com o instrumental que nesse momento possuímos e principalmente com foco na pesquisa. É importante ainda colocar que a dissociação entre 
disciplinas teóricas e práticas não leva a nada, pois elas estão intrinsecamente unidas. Isso se reflete na prática daquilo que nós temos como condição do pensar, do refletir e do conhecer, principalmente. A pesquisa atrelada ao ensino com certeza qualifica muito melhor o ensino do Jornalismo. 